\title{
Hypertension in children from a nephrological perspective - are there any differences between younger children and adolescents?
}

\author{
Karol Marschollek', Paweł Marschollek' ${ }^{1}$ Anna Ciszewska', Julia Rasała', Danuta Zwolińska', \\ Kinga Musiat ${ }^{2}$
}

'Students Scientific Association at the Department of Pediatric Nephrology

${ }^{2}$ Chair and Department of Pediatric Nephrology, Wrocław Medical University

\begin{abstract}
Background. Hypertension (HTN) affects about 5\% of children. Renal diseases are the major cause of HTN in pediatric patients, but the incidence of primary HTN is increasing. The aim of the study was to analyze the potential differences between etiology of HTN, type of renal disease leading to HTN, clinical picture, laboratory test results or family history, with reference to patients' age.

Material and methods. Medical records of 112 patients (27 children $<11$ years and 85 adolescents $>11$ years), diagnosed with hypertension in the Department of Pediatric Nephrology, were analyzed. Family history, aetiology of HTN, clinical course and laboratory results were compared, regarding the patients' age.

Results. HTN secondary to renal disease prevailed over the primary one in younger children. Major causes of renal HTN differed with age. In children under 11 anomalies in the urinary tract were dominant, in teenagers - glomerulopathies. In adolescents, the incidence of primary HTN was higher than in the younger patients and became comparable to that of secondary HTN. Patients with primary HTN, irrespective of their age, had higher BMI and more frequent positive family history of HTN. Clinical symptoms, except for headaches prevalent in adolescents, did not depend on age.

Conclusions. In paediatric patients, hypertension secondary to renal diseases is more frequent than the primary one. The incidence of primary HTN is increasing with age and occurs in adolescents more often than in younger children. The clinical course is usually asymptomatic and may delay the diagnosis, especially in the youngest patients. Key words: primary hypertension; kidney disease; obesity
\end{abstract}

Arterial Hypertens. 2018, vol. 22, no. 4, pages: 179-184 DOI: 10.5603/AH.a2018.0018

\section{Introduction}

Hypertension (HTN) is diagnosed in about $5 \%$ of children and therefore, has become a serious public health problem recently [1]. As a childhood hypertension is a very strong predictor of an adulthood
HTN, it is essential to diagnose it early $[2,3]$. The diagnosis can be established in children whose systolic or diastolic blood pressure (BP) values, measured on at least three separate occasions, are $\geq 95^{\text {th }}$ percentile for age, gender and height or BP is $\geq 120 / 80$

Address for correspondence: Assoc. Prof. Kinga Musiał

Department of Pediatric Nephrology, Wrocław Medical University

Borowska 213, 50-556 Wrocław, Poland, tel./fax: +48 717364400 / 09

e-mail: kinga.musial@umed.wroc.pl

V M Copyright $@ 2018$ Via Medica, ISSN 2449-6170 
$\mathrm{mm} \mathrm{Hg}$ when it comes to adolescents over 16 years old [4]. Its onset may be often asymptomatic or connected with non-specific symptoms, typically a headache and malaise [5]. The incidence of hypertension in the young is increasing constantly, probably due to the childhood obesity epidemic $[6,7]$. In children, secondary hypertension prevails over the idiopathic one. Moreover, kidney diseases are the most frequent cause of hypertension in this population. However, the renal aetiology of secondary HTN strongly depends on age. In neonates, renal vessel thrombosis, prematurity, renal artery stenosis and inborn anomalies of the urinary tract play an important role in the pathogenesis of HTN [4]. As far as children younger than eleven years old are concerned - coarctation of the aorta and neuroblastoma are important causative factors, too. Among adolescents, the incidence of HTN secondary to glomerulopathies increases, and so does the primary HTN [8].

And yet, the diagnosis of HTN in the pediatric population is usually delayed, mainly due to the lack of evident clinical symptoms. The onset of HTN may be often asymptomatic or connected with nonspecific symptoms, like a headache or malaise [5]. Therefore, more attention is being paid to risk factors and predictors of HTN in children. Apart from wellknown indexes like obesity (BMI is the strongest determining factor of HTN [9]) or positive family history, there is much interest in the course of the perinatal period or BP values in infancy and early childhood [5]. However, the data on the subject are inconclusive.

\section{Aim of the study}

The aim of the study was to analyze the potential differences between aetiology of HTN, type of renal disease leading to HTN, clinical picture, laboratory test results or family history, in children diagnosed for HTN, with reference to their age.

\section{Material and methods}

Is was a retrospective study, which comprised medical records of 112 children diagnosed with hypertension in the Department of Pediatric Nephrology. Patients with primary HTN or HTN secondary to kidney disease were included. The diagnosis of HTN was put based on the European Society of Hypertension guidelines [1]. The assessment of $\mathrm{BP}$ values was performed based on reference values for age, gender and percentile of height. We analyzed the data from the hospitalizations, during which the comprehensive diagnosis of hypertension was conclusively established. Preliminary diagnostics concerned kidney diseases. If no anomalies within the urinary tract were observed, further screening covered major endocrine and cardiological causes for HTN. If all the above mentioned investigations revealed no anomalies, the diagnosis of primary HTN was put. The assessed data concerned family history, demographics, aetiology, development, clinical manifestation, and selected laboratory results (serum uric acid and total cholesterol). A positive family history was defined as an occurrence of hypertension or renal disease in at least one of the parents.

The patients were divided into two groups, depending on the age at diagnosis: younger children $(<11$ years old; $\mathrm{n}=27)$ and adolescents $(\geq 11$ years old; $\mathrm{n}=85$ ). In the further analyses, we also subdivided them accordingly to the type of hypertension (primary $v$ s. secondary) in each of the age groups.

All procedures were performed in accordance with the Declaration of Helsinki on the treatment of human subjects.

The study did not require the Ethics Committee approval by the rules and regulations of our University. However, the informed consent regarding the data collection and analysis was obtained from the parents and the patients over 16 .

All authors declare no potential conflicts of interest in relation to this study. No funding was required for the study support.

\section{Statistical analysis}

We performed a univariate quantitative and qualitative analysis using STATISTICA (StatSoft, version 13.0), with significance level $\alpha=5 \%$. Categorical variables were presented as a number and percentage and continuous ones as the mean and standard deviation (SD) or as the median. Chi-squared test for independence and Mann-Whitney $U$ test were used to establish a significance of differences.

\section{Results}

Gender distribution was comparable in both age groups, with a majority of boys (a total of 61.6\%). Irrespectively of age, BMI was higher in patients with primary than with secondary HTN $(\mathrm{p}<0.001)$. When age was taken into account, teenagers with primary HTN had still higher BMI than the ones with secondary HTN ( $\mathrm{p}=0.005)$, but such as- 
Table I. Patient basic characteristics

\begin{tabular}{|c|c|c|c|c|}
\hline \multirow{3}{*}{ Gender } & \multicolumn{2}{|c|}{ Younger children $(n=27)$} & \multicolumn{2}{|c|}{ Adolescents ( $n=85$ ) } \\
\hline & Boys [n; \%] & Girls [n; \%] & Boys [n; \%] & Girls [n; \%] \\
\hline & $16 ; 59 \%$ & $11 ; 41 \%$ & $53 ; 62 \%$ & $32 ; 38 \%$ \\
\hline Median age & \multicolumn{2}{|c|}{7 years } & \multicolumn{2}{|c|}{16 years } \\
\hline \multirow[t]{2}{*}{ Type of HTN } & Primary HTN & Secondary HTN & Primary HTN & Secondary HTN \\
\hline & 6 children $(22.2 \%)$ & 21 children $(77.8 \%)$ & 36 adolescents (42.4\%) & 49 adolescents (57.6\%) \\
\hline \multirow[t]{2}{*}{ BMI $\left[\mathrm{kg} / \mathrm{m}^{2}\right]$} & Primary HTN & Secondary HTN & Primary HTN & Secondary HTN \\
\hline & $17.4 \pm 3.2$ & $15.8 \pm 1.7$ & $25.4 \pm 4.02$ & $22.3 \pm 3.8$ \\
\hline Nutritional status & Primary HTN & Secondary HTN & Primary HTN & Secondary HTN \\
\hline Overweight & 1 child $(16.7 \%)$ & 1 child $(4.7 \%)$ & 15 children $(41.7 \%)$ & 16 children $(32.6 \%)$ \\
\hline Obesity & 2 children $(33.3 \%)$ & & 7 children $(19.4 \%)$ & 2 children (4.1\%) \\
\hline
\end{tabular}

Table II. Causes of secondary hypertension in the analyzed age groups

\begin{tabular}{|l|c|c|c|}
\hline Type of kidney disease $[\mathbf{n}(\%)]$ & Younger children $(\mathbf{n}=\mathbf{2 1})$ & Adolescents $(\mathbf{n}=\mathbf{4 9})$ & $\mathbf{p}$ \\
\hline Glomerulopathy & $2(9.5 \%)$ & $20(40.8 \%)$ & 0.012 \\
\hline Urinary tract anomaly & $17(81 \%)$ & $24(49 \%)$ & 0.03 \\
\hline Hemolytic-uremic syndrome & $2(9.5 \%)$ & $1(2 \%)$ & 0.49 \\
\hline Urolithiasis & $0(0 \%)$ & $4(8.2 \%)$ & 0.43 \\
\hline
\end{tabular}

Table III. Family history in the analyzed age groups

\begin{tabular}{|l|c|c|c|c|c|c|}
\hline \multirow{2}{*}{ Positive family history of: } & \multicolumn{3}{|c|}{ Primary HTN } & \multicolumn{3}{c|}{ Secondary HTN } \\
\cline { 2 - 7 } & $\begin{array}{c}\text { Younger children } \\
(\mathbf{n}=\mathbf{6})\end{array}$ & $\begin{array}{c}\text { Adolescents } \\
(\mathbf{n}=\mathbf{3 6})\end{array}$ & $\mathbf{p}$ & $\begin{array}{c}\text { Younger children } \\
(\mathbf{n}=\mathbf{2 1})\end{array}$ & $\begin{array}{c}\text { Adolescents } \\
(\mathbf{n}=49)\end{array}$ & $\mathbf{p}$ \\
\hline Hypertension & $3(50 \%)$ & $24(66.7 \%)$ & 0.74 & $4(19 \%)$ & $16(32.7 \%)$ & 0.25 \\
\hline Kidney diseases & $1(16.7 \%)$ & $5(13.9 \%)$ & 0.65 & $6(28.6 \%)$ & $13(26.5 \%)$ & 0.86 \\
\hline
\end{tabular}

sociation was not confirmed in younger children $(\mathrm{p}=0.6)$. However, adolescents with both primary $(\mathrm{p}=0.005)$ and secondary $(\mathrm{p}<0.001)$ HTN had higher BMI than corresponding groups of younger children (Table I). Moreover, over $60 \%$ of adolescents with primary HTN were either overweight or obese (Table I).

In the group of younger children, hypertension secondary to renal diseases dominated over the primary HTN (78\%; $p=0.004)$. In adolescents, such preponderance was not observed, as both types occurred with a comparable frequency (primary: $42 \%$ vs. secondary: $58 \% ; \mathrm{p}=0.16$ ). Among the causes of HTN secondary to renal diseases, glomerulopathies were significantly more common in adolescents, whereas urinary tract anomalies were more frequent in younger children (Table II).

A positive family history of hypertension was more often noticed in children with primary than with secondary HTN, irrespective of their age $(\mathrm{p}<$
0.001). There was no difference in the occurrence of kidney diseases in the family history between primary and secondary HTN ( $\mathrm{p}=0.23)$ or between age groups (Table III). The most common conditions were glomerulonephritis and urolithiasis.

Nineteen younger children (70.4\%) and 39 adolescents (45.9\%) were asymptomatic. Headaches were more frequently reported in the older group, the incidence of other symptoms was not related to age (Table IV).

Younger children with primary hypertension had significantly higher cholesterol serum level than the corresponding group of adolescents $(305 \pm 87.7 \mathrm{ng} \mathrm{dl}$ vs. $170.5 \pm 47.1 \mathrm{ng} / \mathrm{dl} ; \mathrm{p}=0.04)$. In the case of secondary HTN, no differences between age groups were found $(199.5 \pm 47.3 \mathrm{ng} / \mathrm{dl} v s .203 .7 \pm 67.3 \mathrm{ng} / \mathrm{dl}$ respectively; $p=0.95)$. When the whole groups of patients with primary and secondary HTN were compared, no significant difference in cholesterol level was established either $(\mathrm{p}=0.07)$. 
Table IV. The clinical picture of HTN in the analyzed age groups

\begin{tabular}{|l|c|c|c|}
\hline Symptom & Younger children (n = 27) & Adolescents (n = 85) & p \\
\hline Headaches & $3(11.1 \%)$ & $31(36.5 \%)$ & 0.02 \\
\hline Abdominal pain & $5(18.5 \%)$ & $18(21.2 \%)$ & 0.75 \\
\hline Vomiting & $2(7.4 \%)$ & $10(11.8 \%)$ & 0.52 \\
\hline Malaise & $3(11.1 \%)$ & $11(12.9 \%)$ & 0.8 \\
\hline Epistaxis & $1(3.7 \%)$ & $7(8.2 \%)$ & 0.43 \\
\hline Heart palpitations & $1(3.7 \%)$ & $7(8.2 \%)$ & 0.43 \\
\hline Dyspnoea & $1(3.7 \%)$ & $9(10.6 \%)$ & 0.27 \\
\hline
\end{tabular}

Concerning serum uric acid, no differences between age groups were observed in primary $(6.7 \pm$ $1.3 \mathrm{ng} / \mathrm{dl} v$ s. $5.5 \pm 0.97 \mathrm{ng} / \mathrm{dl} ; \mathrm{p}=0.25$ ) or secondary HTN (5.7 $\pm 1.6 \mathrm{ng} / \mathrm{dl} v$ s. $5.4 \pm 1.3 \mathrm{ng} / \mathrm{dl} ; \mathrm{p}=0.38)$. The values in both types of HTN, irrespective of age, were also comparable $(\mathrm{p}=0.42)$

\section{Discussion}

In our study, we searched for the potential differences between children and adolescents with HTN, in regards to hypertension aetiology, medical and family history, clinical manifestations and laboratory results.

Renal etiology of hypertension is still dominant in the pediatric population and our results seem to confirm these observations. In the group of younger children, hypertension secondary to renal disease was significantly more common (78\%), whereas in the group of adolescents the difference was less noticeable - secondary HTN was observed in 58\% of patients.

As in the other studies [10], the most common cause of renal secondary HTN were urinary tract abnormalities, irrespective of the child's age. However, they strongly prevailed in younger children $(81 \%$ of secondary HTN), whereas adolescents suffered from glomerular diseases with comparable frequency to that of anomalies in the urinary tract (40 vs. 49\%). These discrepancies show that although the prevalence of primary HTN increases with age, kidney diseases are still in the first line and the diagnostics of HTN in the pediatric population should always take into account the renal perspective. The early diagnosis of secondary HTN in younger children seems of paramount importance, mainly due to the subsequent end-organ damage that may develop during the course of the disease, despite the initially asymptomatic or non-specific clinical picture $[11,12]$.

The growing frequency of primary hypertension, reported in recent years among adolescents [13-15], was concordant with our observations. Some of the authors defined an even greater prevalence of primary HTN over the secondary one in the studied groups $[10,16,17]$. The increasing role of primary hypertension in adolescents may be connected to the childhood obesity epidemic [18-21]. In our study, the majority of adolescents with primary HTN were either overweight or obese. In the study carried out in a single paediatric centre in Poland in the 90s, no case of primary hypertension was recorded in the group < 14 years old, whereas over 20 years later, in this group $<11$ years old, the authors noticed 22\% of primary HTN [22].

The disproportion between younger children and adolescents in this study group was another intriguing finding - teenagers were three times more numerous than younger patients. This discrepancy may result from the pre-selection of pediatric patients admitted to our Department. The preliminary screening takes place in the outpatients, where the impact is put mainly on the diagnosis of secondary reasons for HTN. If major cardiological or endocrine abnormalities are detected, the patients are admitted to the tertiary reference centre for further detailed diagnostics. Thus, the group of children admitted to the Department of Pediatric Nephrology, consisted of those in whom a kidney disease was diagnosed, and of those with a suspicion of primary HTN, thus — mainly adolescents. Another, potentially alarming explanation of this phenomenon, may be the fact that the possibility of small children to develop hypertension is usually neglected. Taken together with the overt clinical course, the suspicion is that many of the cases of pediatric HTN, especially in younger children, are overlooked and, thus, diagnosed in adolescence or even adulthood.

No difference was observed in the occurrence of a positive family history of hypertension or renal disease between the two age groups. However, we observed a significantly higher prevalence of a positive family history of hypertension in patients with 
primary HTN than the secondary one, which is concordant with other reports $[10,13,16]$.

The data on differences in the clinical picture of hypertension between various age groups are scarce. Detailed analysis of patients' complaints is important in the diagnostic process due to the overt clinical course or non-specific symptoms.

Some authors emphasize the more frequent presence of symptoms at the moment of diagnosis in children with secondary hypertension [13], others show no difference in the occurrence of such symptoms as a headache or vision changes [10]. In the authors' observation, the clinical picture did not depend on the age of patients. The only exception concerned headaches that were significantly more common among teenagers. $70 \%$ of younger children and $46 \%$ of adolescents were asymptomatic, which created a higher value than in other publications $[13,23]$.

In the study group, BMI was significantly higher in children with primary than with secondary HTN. However, such a difference was found only in adolescents. This discrepancy may result from a relatively small number of younger children in this analysis.

The authors have found younger children with primary hypertension to present with significantly higher total cholesterol level than adolescents, which is convergent to another study [17], where the highest level of total cholesterol was observed in a group of school children (6-12 years old).

This study has limitations. The analyzed group was not representative of all secondary causes of HTN, yet analyzed in detail the renal ones. The disproportion between the number of younger children and adolescents could also form a bias towards relations between age groups. Therefore, the observation will be continued, in order to enable drawing further conclusions, based on a larger group of paediatric patients with HTN.

\section{Conclusions}

In younger children, hypertension secondary to kidney disease dominated over the primary HTN. The prevalence of the latter increased with age, yet renal anomalies remained the equally important reason for HTN in adolescents.

The asymptomatic course of HTN was recorded in nearly $75 \%$ of younger children and $50 \%$ of teenagers. Thus, attention should be paid to regular blood pressure control in paediatric patients, irrespective of their age.
Children with any kind of kidney disease should be followed up carefully, regarding the threat of developing secondary hypertension.

\section{References}

1. Lurbe E, Agabiti-Rosei E, Cruickshank JK, et al. 2016 European Society of Hypertension guidelines for the management of high blood pressure in children and adolescents. J Hypertens. 2016; 34(10): 1887-1920, doi: $10.1097 / \mathrm{HJH} .0000000000001039$, indexed in Pubmed: 27467768.

2. Chen X, Wang Y. Tracking of Blood Pressure From Childhood to Adulthood: A Systematic Review and Meta-Regression Analysis. Circulation. 2008; 117(25): 3171-3180, doi: 10.1161/circulationaha.107.730366.

3. Tirosh A, Afek A, Rudich A, et al. Progression of normotensive adolescents to hypertensive adults: a study of 26,980 teenagers. Hypertension. 2010; 56(2): 203-209, doi: 10.1161/HYPERTENSIONAHA.109.146415, indexed in Pubmed: 20547973.

4. Żurowska A, Zwolińska D, Roszkowska-Blaim M, et al. Rekomendacje Polskiego Towarzystwa Nefrologii Dziecięcej (PTNFD) dotyczące postępowania z dzieckiem z podwyższonym ciśnieniem tętniczym. Forum Medycyny Rodzinnej. 2015; 9(5): 349-375.

5. Widecka K. Nadciśnienie tętnicze u dzieci i młodzieży — coraz większy problem medyczny. Chor Serca Naczyń. 2004; 1(2): 89-96.

6. Falkner B. Hypertension in children and adolescents: epidemiology and natural history. Pediatr Nephrol. 2010; 25(7): 1219-1224, doi: 10.1007/s00467-009-1200-3, indexed in Pubmed: 19421783.

7. Ogden CL, Flegal KM, Carroll MD, et al. Prevalence and trends in obesity among US adults, 1999-2000. JAMA. 2002; 288(14): 1723-1727, doi: 10.1001/jama.288.14.1728, indexed in Pubmed: 12365955.

8. Sorof JM, Lai D, Turner J, et al. Overweight, Ethnicity, and the Prevalence of Hypertension in School-Aged Children. PEDIATRICS. 2004; 113(3): 475-482, doi: 10.1542/peds.113.3.475.

9. Katona E, Zrínyi M, Komonyi E, et al. Epidemiological data of 15-18 year adolescents and the prevalence of hypertension in Debrecen. The Debrecen Hypertension Study. Orv Hetil. 2005; 146(3): 127-132, doi: 10.3109/08037051.2010.538987, indexed in Pubmed: 15693444.

10. Baracco R, Kapur G, Mattoo T, et al. Prediction of primary vs secondary hypertension in children. J Clin Hypertens (Greenwich). 2012; 14(5):316-321, doi: 10.1111/j.1751-7176.2012.00603.x, indexed in Pubmed: 22533658.

11. Litwin M, Michałkiewicz J, Gackowska L. Primary hypertension in children and adolescents is an immuno-metabolic disease with hemodynamic consequences. Curr Hypertens Rep. 2013; 15(4):331-339, doi: 10.1007/s1 1906-013-0360-5, indexed in Pubmed: 23737217.

12. Silva AC. Pathophysiology of Arterial Hypertension: Insights from Pediatric Studies. Current Pediatric Reviews. 2006; 2(3): 209-223, doi: 10.2174/157339606778019684.

13. Gomes RS, Quirino IG, Pereira RM, et al. Primary versus secondary hypertension in children followed up at an outpatient tertiary unit. Pediatr Nephrol. 2011; 26(3): 441-447, doi: 10.1007/s00467-0101712-x, indexed in Pubmed: 21174218.

14. DiPietro A, Kees-Folts D, DesHarnais S, et al. Primary hypertension at a single center: treatment, time to control, and extended follow-up. Pediatr Nephrol. 2009; 24(12): 2421-2428, doi: 10.1007/s00467009-1297-4, indexed in Pubmed: 19714367.

15. Flynn JT, Alderman MH. Characteristics of children with primary hypertension seen at a referral center. Pediatr Nephrol. 2005; 20(7): 961-966, doi: 10.1007/s00467-005-1855-3, indexed in Pubmed: 15864653.

16. Gupta-Malhotra M, Banker A, Shete S, et al. Essential hypertension vs. secondary hypertension among children. Am J Hypertens. 2015; 28(1): 73-80, doi: 10.1093/ajh/hpu083, indexed in Pubmed: 24842390. 
17. Flynn J, Zhang Y, Solar-Yohay S, et al. Clinical and demographic characteristics of children with hypertension. Hypertension. 2012; 60(4): 1047-1054, doi: 10.1161/HYPERTENSIONAHA.112.197525, indexed in Pubmed: 22892814.

18. Flynn J. The changing face of pediatric hypertension in the era of the childhood obesity epidemic. Pediatr Nephrol. 2013; 28(7): 1059-1066, doi: 10.1007/s00467-012-2344-0, indexed in Pubmed: 23138756.

19. Kapur G, Ahmed M, Pan C, et al. Secondary hypertension in overweight and stage 1 hypertensive children: a Midwest Pediatric Nephrology Consortium report. J Clin Hypertens (Greenwich). 2010; 12(1): 34-39, doi: 10.1111/j.1751-7176.2009.00195.x, indexed in Pubmed: 20047628.

20. Hansen ML, Gunn PW, Kaelber DC. Underdiagnosis of hypertension in children and adolescents. JAMA. 2007;
298(8): 874-879, doi: 10.1001/jama.298.8.874, indexed in Pubmed: 17712071.

21. Assadi F. The growing epidemic of hypertension among children and adolescents: a challenging road ahead. Pediatr Cardiol. 2012; 33(7): 1013-1020, doi: 10.1007/s00246-012-0333-5, indexed in Pubmed: 22565200.

22. Wyszyńska T, Cichocka E, Wieteska-Klimczak A, et al. A single pediatric center experience with 1025 children with hypertension. Acta Paediatr. 1992; 81(3): 244-246, doi: 10.1111/j.1651-2227.1992. tb12213.x, indexed in Pubmed: 1511199.

23. Kota SK, Kota SK, Meher LK, et al. Clinical analysis of hypertension in children: an urban Indian study. Saudi J Kidney Dis Transpl. 2013; 24(4): 844-852, doi: 10.4103/1319-2442.113919, indexed in Pubmed: 23816747. 